\title{
Dental anxiety among dental, medical, and nursing students of two major universities in the central region of the Kingdom of Saudi Arabia: a cross-sectional study
}

Reham AL Jasser ${ }^{1 *}$, Ghaida Almashaan², Haya Alwaalan², Najla Alkhzim² and Abdulrhman Albougami ${ }^{3}$

\begin{abstract}
Background: Dental anxiety is one of the most common fears that can eventually lead to avoidance of dental care. Knowing how students will respond to dental treatment will aid in increasing their awareness of oral health and overcoming this fear. The present study measured the prevalence of dental anxiety among dental, medical, and nursing students in Riyadh city, Kingdom of Saudi Arabia.

Methods: A cross-sectional study including undergraduate dental, medical, and nursing students at King Saud University and Almajmaa University was conducted to assess dental anxiety using the Modified Dental Anxiety Scale. Descriptive statistics including means, standard deviations, and percentages were calculated. Group comparisons were analyzed using t-tests and analysis of variance. Multiple group comparisons were conducted using Tukey's post-hoc test. $P<0.05$ was considered as the significance level.

Results: Two hundred twenty-four participants completed the questionnaire. Medical students accounted for most of the responses (40.6\%), followed by nursing (31.7\%), and dental students (27.7\%). There was no significant difference in dental anxiety with regard to gender. Dental students exhibited the least dental anxiety. A significant difference was found between students with good dental experiences compared with those who had bad dental experiences.

Conclusion: Dental students had the lowest level of anxiety and anxiety levels were affected by previous dental visits. Increasing awareness and knowledge about oral health, regular dental education, and incorporating dental knowledge into university curriculums can aid in eliminating the fear of dentistry among health sciences students.
\end{abstract}

Keywords: Anxiety scale, Dental, Medical students, Dental students, Nursing students

\section{Background}

Despite advancements and new technologies used in dental treatment, dental anxiety is still considered one of the most common fears [1]. It can be defined as an exaggerated psychological apprehensive response of an individual to perceived dental treatment and can affect people of any gender, age, or social status [2, 3]. Dental anxiety could lead to avoidance of dental treatment and affect the patient both psychologically and physically by

\footnotetext{
* Correspondence: raljasser@ksu.edu.sa

${ }^{1}$ Department of Periodontics and Community Dentistry, College of Dentistry, King Saud University, PO Box 60169, Riyadh 11545, Saudi Arabia Full list of author information is available at the end of the article
}

affecting their eating habits, decreasing their confidence in their teeth, and avoiding smiling [4]. This process could lead to deterioration in oral health and give rise to an unbearable problem after which the anxious individual will inevitably visit the dentist [5].

In previous research, dental anxiety was associated with traumatic past dental experiences, irregular dental visits, and a lack of dental awareness [2]. It can also affect the dentist-patient relationship, causing an increase in chair time, inaccurate diagnosis, and treatment setbacks [5-7]. Dental anxiety may affect the dentist as well, by increasing the dentist's level of stress while providing dental treatment [5]. 
Several studies have investigated dental anxiety in university students; specifically, how dental students compare with students in other disciplines of study. Al-Omari et al. concluded that dental students had lower levels of dental anxiety than non-dental students, owing to their dental education and awareness of most clinical procedures [3]. Another study conducted in Malaysia also found that dental students had lower levels of dental anxiety than medical and pharmacy students, and for similar reasons [5]. Furthermore Storjord et al. [8] showed differences in the degree of dental anxiety among dental students according to their education level. Senior dental students had lower levels of dental anxiety than junior students, owing to more exposure to different dental procedures during their years spent in college, which was considered as a form of exposure therapy (environmental habituation). Thus, dental education along with clinical experience might reduce this anxiety [8]. All previously discussed studies highlighted the significance of lowering dental anxiety, which can lead to better acceptance of dental treatment, and thereby improve quality of life. This can be initiated by determining the level of dental anxiety initially present and its relationship to the amount of personal knowledge regarding dentistry.

Therefore, the purpose of the present study was to measure the prevalence of dental anxiety among dental, medical, and nursing students in Riyadh city, Kingdom of Saudi Arabia. The Modified Dental Anxiety Scale was used to assess dental anxiety. Additionally, we explored differences in the degree of dental anxiety according to gender, field of study, and dental treatment experience.

\section{Methods}

\section{Study sample}

The sample size was determined by G*Power software, with a confidence level set at $95 \%$, power set at $80 \%$, and a moderate effect size, which indicated a final sample size of 200 subjects. However, to avoid a low response rate, which could affect the sample size, a larger sample than that calculated was recruited, based on the assumption that not every individual in the sample would respond to the study. A final sample of 300 participants was targeted using purposive sampling.

Using a cross-sectional research design, the study involved survey research with dental, medical, and nursing undergraduate students from two different educational institutes in Riyadh, Saudi Arabia (King Saud University and Al Majmaa University). The students were in their third, fourth, and fifth year of college.

\section{Recruitment strategy}

The researchers reserved a lecture room in which to conduct the study. Tables in the lecture room were marked with a reserved sign to increase the participants' comfort level to sit and answer the survey questionnaires without interference or interruption by non-participants. Next, the researchers distributed flyers to recruit potential research participants. Interested participants could stop by the room to determine their eligibility. Eligible participants completed the informed consent forms prior to completing the survey questionnaires and returning them to the researcher. The objective of the study was explained to the students and any questions they had were answered. The anticipated time to complete the consent form and questionnaire was approximately 30 min. Finally, a total of 300 eligible students participated.

All responses were recorded anonymously and voluntarily. Students were informed that they have the right to discontinue from the study at any point in time without any consequence, and that the confidentiality of their responses would be maintained.

The Arabic version of the Modified Dental Anxiety Scale (MDAS) was used to assess dental anxiety [9]. The MDAS is considered a valid and reliable measure [5] and consists of five questions as follows: (1) If you went to your dentist for treatment tomorrow, how would you feel? (2) If you were sitting in the waiting room, how would you feel? (3) If you were about to have a tooth drilled, how would you feel? (4) If you were about to have your teeth scaled and polished, how would you feel? (5) If you were about to have a local anesthetic injection in your gum, how would you feel? Each question has five responses ranging from 1 (not anxious) to 5 (extremely anxious). The MDAS score is the sum of the five responses and can range from 5 to 25 . A score of 19 or above is considered as dentally anxious, $12-18$ mildly dentally anxious, and 5-11 as not anxious at all. Cronbach's alpha for the MDAS was 0.86 in the present study, suggesting good internal consistency reliability. In addition to the MDAS, participants were asked about their gender, age, college specialty, and dental treatment experiences.

Descriptive statistics including means, standard deviations, and percentages were calculated. Group comparisons were analyzed using two-tailed Student's t-tests as well as one-way analysis of variance. Multiple group comparisons were conducted using Tukey's post-hoc test. $P<0.05$ was considered as the significance level.

\section{Results}

Out of 300 students, a total of 224 participants completed the questionnaire. Table 1 provides statistics on the participants' age, gender, and field of study. The majority of respondents were female (75.9\%) and were 18 22 years old (54.5\%). Most of the participants were studying medicine (40.6\%), followed by nursing (31.7\%) then dentistry (27.7\%). The mean MDAS score of the 
Table 1 Distribution of participants according to age, gender, and field of study

\begin{tabular}{lll}
\hline Gender & Number $(n)$ & Percent (\%) \\
Male & 54 & 24.1 \\
Female & 170 & 75.9 \\
Age & & \\
$18-22$ & 122 & 54.5 \\
$23-27$ & 81 & 36.2 \\
More than 30 & 21 & 9.4 \\
Field of study & & \\
Medicine & 91 & 40.6 \\
Nursing & 71 & 31.7 \\
Dentistry & 62 & 27.7 \\
Total & 224 & 100.0 \\
\hline
\end{tabular}

sample was 14 , and $65.2 \%$ of the students were categorized as having a low level of dental anxiety. Only 18 participants were considered to have significant dental anxiety (Tables 2 and 3). Fifty-two percent reported that they visit the dentist only when having a dental problem, and $51 \%$ reported that their last dental visit was 6 months ago.

When examining gender and dental anxiety, there was no significant difference in MDAS score between men

Table 2 Distribution of MDAS scores among participants

\begin{tabular}{lll}
\hline Score & Frequency $(n)$ & Percent $(\%)$ \\
\hline 5 & 26 & 11.6 \\
6 & 25 & 11.2 \\
7 & 20 & 8.9 \\
8 & 19 & 8.5 \\
9 & 20 & 8.9 \\
10 & 21 & 9.4 \\
11 & 15 & 6.7 \\
12 & 8 & 3.6 \\
13 & 9 & 4.0 \\
14 & 13 & 5.8 \\
15 & 11 & 4.9 \\
16 & 9 & 4.0 \\
17 & 5 & 2.2 \\
18 & 5 & 2.2 \\
19 & 6 & 2.7 \\
20 & 2 & 0.9 \\
21 & 3 & 2.3 \\
22 & 3 & 1.3 \\
24 & 2 & 0.9 \\
25 & 2 & 0.9 \\
Total & 224 & 100.0 \\
\hline
\end{tabular}

Table 3 Distribution of anxiety levels among participants

\begin{tabular}{lll}
\hline & Frequency $(n)$ & Percent (\%) \\
\hline Low anxiety & 146 & 65.2 \\
Moderate anxiety & 41 & 18.3 \\
High anxiety & 19 & 8.5 \\
Severe anxiety & 18 & 8.0 \\
Total & 224 & 100.0 \\
\hline
\end{tabular}

$(M=9.63, \quad S D=3.728)$ and women $(M=10.98, \quad S D=$ 5.009) $(P=0.069)$. On the other hand, when the field of study was compared, significant differences were found between dental students $(M=9.15, S D=4.136)$ and nursing students $(M=12.55, \quad S D=4.972) \quad(P=0.000)$. There was also a significant difference between medical students $(M=10.21, S D=4.634)$ and nursing students $(P=0.004)$. However, there was no significant difference in dental anxiety between medical students and dental students $(P=0.480)$ (Tables 4 and 5$)$.

When examining dental experiences, participants with good dental experiences had lower scores on the MDAS $(M=10.13, S D=4.364)$ compared to those who had bad dental experiences $(M=15.45, S D=5.621) \quad(P=0.000)$. Additionally, participants who had visited a recommended or previously known dentist had lower scores on the MDAS $(M=9.74, S D=4.070)$ compared to those who were meeting a dentist for the first time $(M=14.62$, $S D=5.504)(P=0.000)$.

\section{Discussion}

The purpose of the present study was to investigate the prevalence of dental anxiety among dental, medical, and nursing students in Riyadh city, Kingdom of Saudi Arabia. To this end, the Modified Dental Anxiety Scale was used to assess dental anxiety in the participants. Overall, the mean scores for the three categories of students indicate they were not dentally anxious at all or were mildly dentally anxious. Findings of this study revealed that dental students had a lower level of dental anxiety than medical students, although both groups' scores indicate they were not dentally anxious at all. Nursing students had the highest score, which indicated they were mildly dentally anxious.

The results in the present study are in agreement with those reported by Al-Omari and Al-Omiri, in which dental students had lower levels of dental anxiety when

Table 4 MDAS mean scores of medical, dental, and nursing students

\begin{tabular}{lll}
\hline & Mean & Std. deviation \\
\hline Medicine & 10.21 & 4.634 \\
Dentistry & 9.15 & 4.136 \\
Nursing & 12.55 & 4.872 \\
\hline
\end{tabular}


Table 5 Multiple comparisons among fields of study

\begin{tabular}{llllll}
\hline (I) Field of Study & $(J)$ Field of Study & Mean Difference (I-J) & Standard Error & $P$ value & $95 \%$ Lower Bound \\
\hline Medicine & Nursing & -2.341 & .725 & .004 & -4.09 \\
& Dentistry & 1.064 & .754 & .480 & -.76 \\
Nursing & Dentistry & 3.404 & .796 & .000 & 1.48 \\
& Medicine & 2.341 & .725 & .004 & .59 \\
Dentistry & Nursing & -3.404 & .796 & .000 & -5.33 \\
& Medicine & -1.064 & .754 & .480 & -2.88 \\
\hline
\end{tabular}

compared to medical students [3]. Similarly, Thomas et al. showed that dental students had lower levels of dental anxiety compared to medical and nursing students [2]. These findings can be justified by the knowledge and background that dental students gain through their studies, which would aid in reducing their anxiety by knowing some of the details about each dental procedure. However, somewhat contrary to prior research, there was no statistically significant difference in dental anxiety between medical and nursing students, even though their scores fell in different clinical ranges [10]. Thomas et al. and Al-Omari and Al-Omiri found that medical students experienced high levels of dental anxiety compared to students from other non-health fields of study $[2,3]$. It can be hypothesized that when comparing nursing and medical fields of study, the students have similar knowledge owing to sharing various courses, as well as sharing relatively similar exposure to the same professional environment, which may explain their different perception of dental interventions compared to dental students. Overall, and consistent with the previously mentioned studies, it can be argued that the knowledge gained through dental education is a major factor in reducing dental anxiety. This observation is supported by other studies that have been done in other countries. For example, in 2014 a study of undergraduate students at Al-Quds University in Palestine found that dental students were less anxious compared to medical and pharmacy students. Similarly, an Indian study revealed that non-dental students expressed more dental anxiety due to lack of dental education in their curriculum $[2,3,10]$.

There were interesting findings when examining gender and past dental experiences in relation to dental anxiety. Male and female students did not differ in their level of dental anxiety, which is in agreement with another study that was conducted in the Kingdom of Saudi Arabia [11]. However, it is inconsistent with previous studies done in the same region that found that female students had higher levels of dental anxiety [2, 3, 12]. Not surprisingly, students who have had a bad dental experience reported higher levels of dental anxiety than those who have had good dental experiences. Thus, it is safe to say that positive experiences can potentially reduce dental anxiety levels.
Limitations of the present study include a larger number of females compared to males in the sample, which was due to limited access to male students within both institutes. Data were only collected from two institutes in the region, which may not be representative of the population because students' knowledge and backgrounds may differ between different educational institutes in the country because of different curriculums. Therefore, further long-term studies with a larger sample size representing all institutes and regions in the country are recommended to more precisely assess the level of dental anxiety, so that suitable curriculums can be implemented to overcome this concern.

\section{Conclusion}

Dental anxiety was lowest among dental students when compared to medical students and nursing students. In addition, the level of anxiety was influenced by whether previous dental experiences were good or bad. Therefore, eliminating the fear of dentistry could be achieved by providing regular dental education and implementing initiatives that promote awareness and knowledge about oral health [13]. As such, university curriculums should focus on increasing dental knowledge as a means of overcoming fear of dental treatment among university health sciences students [2].

\section{Abbreviation \\ MDAS: Modified dental anxiety scale}

\section{Acknowledgements}

The authors would like to thank the College of Dentistry Research Center at King Saud University, Riyadh, Saudi Arabia for all the support provided for this study in terms of revising the manuscript and distributing the surveys.

Funding

Not applicable.

\section{Availability of data and materials}

The datasets generated and/or analyzed during the current study are not publicly available due to interest of protecting subjects' confidentiality but are available from the corresponding author on reasonable request.

Authors' contributions

RJ proposed the research idea and applied methodology, and contacted the main survey's author for approval of use; HW, GM, and NK helped in survey distribution and data collection; $A B$ did the statistical analysis and interpretation of the data. RJ reviewed the final manuscript. All authors read and approved the final manuscript. 


\section{Ethics approval and consent to participate}

The protocol used in this study was approved by the Institutional Committee of Research Ethics at the College of Dentistry Research Center, King Saud University, Riyadh, Saudi Arabia. Permission to collect the data used in the study was granted by the institutional review board at King Saud University and Majmaah University, Majmaah, Saudi Arabia (ID \# 32145698). The research was conducted in full accordance with the World Medical Association Declaration of Helsinki. Written informed consent was obtained from the students prior to participating in the study, and they were informed that personal information would not be collected.

\section{Consent for publication}

Not applicable

\section{Competing interests}

The authors declare that they have no competing interests.

\section{Publisher's Note}

Springer Nature remains neutral with regard to jurisdictional claims in published maps and institutional affiliations.

\section{Author details}

'Department of Periodontics and Community Dentistry, College of Dentistry, King Saud University, PO Box 60169, Riyadh 11545, Saudi Arabia. ${ }^{2}$ College of Dentistry, King Saud University, Riyadh, Saudi Arabia. ${ }^{3}$ Department of Nursing, College of Applied Medical Sciences, Majmaah University, Almajmaah 11952, Saudi Arabia.

Received: 15 January 2019 Accepted: 3 April 2019

Published online: 15 April 2019

\section{References}

1. do Nascimento DL, da Silva Araújo AC, Gusmão ES, et al. Anxiety and fear of dental treatment among users of public health services. Oral Health Prev Dent. 2011:9:329-37.

2. Thomas M, Kumar V, Sooraparaju S, et al. Dental anxiety among dental, medical, and nursing students in India and its correlation with their field of study. J Int Oral Health. 2016;8:860-4.

3. Al-Omari WM, Al-Omiri MK. Dental anxiety among university students and its correlation with their field of study. J Appl Oral Sci. 2009;17:199-203.

4. Moore R, Brødsgaard I, Rosenberg N. The contribution of embarrassment to phobic dental anxiety: a qualitative research study. BMC Psychiatry. 2004;4: 10.

5. Gunjal S, Pateel DGS, Parkar S. Dental anxiety among medical and paramedical undergraduate students of Malaysia. Int J Dent. 2017;2017:1-5.

6. Armfield JM, Slade GD, Spencer AJ. Dental fear and adult oral health in Australia. Community Dent Oral Epidemiol. 2009;37:220-30.

7. Frazer M, Hampson S. Some personality factors related to dental anxiety and fear of pain. Br Dent J. 1988;165:436-9.

8. Storjord HP, Teodorsen MM, Bergdahl J, et al. Dental anxiety: a comparison of students of dentistry, biology, and psychology. J Multidiscip Healthc. 2014:7:413-8.

9. Al-Nasser L, Yunus F, Ahmed A. Validation of Arabic version of the modified dental anxiety scale and assessment of cut-off points for high dental anxiety in a Saudi population. J Int Oral Health. 2016;8(1):21-6.

10. Abu Hantash RO, Abu Younis MH, Aker MM. Dental anxiety and fear among medical field students at Al Quds University. Br J Med Res. 2014;4:2312-21.

11. Alshammary $M$, Alhumaid $M$, Alnejeem $G$, et al. Dental anxiety among medical field students in University of Hail, Saudi Arabia [internet] Saspjournals.com; 2017. https://pdfs.semanticscholar.org/41f3/ a2db7c25109d9282d48bab44d547103f8562.pdf. Accessed 11 Nov 2018.

12. Sghaireen MG, Zwiri AM, Alzoubi IA, et al. Anxiety due to dental treatment and procedures among university students and its correlation with their gender and field of study. Int J Dent. 2013;2013:647436.

13. Ogwo, C. Prevalence of dental anxiety among Western Illinois University students. 2018. http://www.wiu.edu/graduate_studies/graduate_research_ conference/GRC-2018-Abstracts.pdf. Accessed 20 Oct 2018.

\section{Ready to submit your research? Choose BMC and benefit from:}

- fast, convenient online submission

- thorough peer review by experienced researchers in your field

- rapid publication on acceptance

- support for research data, including large and complex data types

- gold Open Access which fosters wider collaboration and increased citations

- maximum visibility for your research: over $100 \mathrm{M}$ website views per year

At BMC, research is always in progress.

Learn more biomedcentral.com/submissions 